\title{
A History of Multiple Sclerosis Investigations in Canada Between 1850 and 1950
}

\author{
Aravind Ganesh, Frank W. Stahnisch
}

\begin{abstract}
The medical profession's modern quandaries with Multiple Sclerosis (MS) largely began in 1849, with Friedrich von Frerichs' (1819-1885) early description of the clinical and pathological features of what he termed Hirnsklerose ("brain sclerosis"). This manuscript is an overview of the century of research (1850-1950) that followed the emergence of this clinical entity, with a focus on the hitherto under-explored English Canadian perspective. Using journal articles, reviews, and case studies, this historiographical paper reviews what may be some of the earliest recorded cases of MS in Canada, and outlines the diagnostic challenges that confronted early Canadian physicians in their encounters with MS. Early Canadian attempts to characterize the aetiology and epidemiology of MS and treat it are also discussed. These activities were influenced by developments in the field in Europe and the United States, and helped set the stage for the modern era of immunologic and therapeutic research on MS.
\end{abstract}

RÉSUMÉ: Histoire de la recherche sur la sclérose en plaques au Canada entre 1850 et 1950 . Les dilemmes rencontrés par la profession médicale concernant la sclérose en plaques (SP) sont connus depuis 1849, suite à la description initiale faite par Friedrich von Frerichs (1819-1885) des manifestations cliniques et pathologiques de ce qu'il a appelé l'Hirnsklerose ( sclérose du cerveau »). Nous présentons un survol de la recherche effectuée de 1850 à 1950 suite à cette description clinique de la maladie et nous mettons l'accent sur la perspective du Canada anglais, ce qui n'a beaucoup été étudié à ce jour. Nous avons utilisé des articles de journaux, de revues et des études de cas pour revoir dans ce compte rendu historiographique ce qui pourrait constituer quelques-uns des tout premiers cas de SP publiés au Canada et nous décrivons les défis diagnostiques auxquels les médecins canadiens de cette période étaient confrontés face à leurs patients atteints de SP. Nous discutons des tentatives canadiennes de cette époque de caractériser l'étiologie et l'épidémiologie de la SP et son traitement. Ces activités ont été influencées par les développements dans ce domaine en Europe et aux États-Unis et ont aidé à jeter les bases de la recherche immunologique et thérapeutique sur la SP à l'époque moderne.

Can J Neurol Sci. 2014; 41: 320-332

\section{Multiple Sclerosis}

Multiple sclerosis (MS) is a chronic, debilitating, presently incurable demyelinating disease of the central nervous system (CNS), affecting close to 2.5 million people worldwide ${ }^{1}$. The existence of this disease as an agglomeration of symptoms such as motor, sensory, autonomic, and visual impairments ${ }^{2}$ became evident in the 19th century through the observations of the British pathologist Robert Carswell (1793-1857) and the French surgeon-anatomist Jean Cruveilhier (1791-1874), who produced detailed drawings of spinal cord dissections with the distinctive sclerotic plaques now known to be associated with $\mathrm{MS}^{3}$. The disease frame of MS itself only took shape in the latter half of the 19th century, when the combination of advances in clinical descriptions and neuropathology enabled the individualization and classification of this and similar neurological diseases ${ }^{4}$. In fact, the medical profession's practical quandaries with MS as a distinct disease entity may be traced back to 1849 , with the early description of the clinical and pathological features of the disease - termed Hirnsklerose ("brain sclerosis") - by the German pathologist Friedrich Theodor von Frerichs (18191885), who also recognized the phenomena of remissions, and the presence of cognitive deficits in MS patients ${ }^{3}$.
The century that followed the emergence of this clinical entity has been described by Hans Lassmann, a leading Austrian neuropathologist at the University of Vienna, as a "golden centenium" for the evolution of medical understanding of $\mathrm{MS}^{5}$, and a similar account is also given in Canadian neurologist Thomas Jock Murray's book, Multiple Sclerosis: The History of a Disease ${ }^{6}$. With a view to the particular Canadian place in the history of MS research, a very interesting conundrum arises: although Canada has one of the highest prevalence rates for MS in the world at 240 individuals per 100,000 population nationally ${ }^{7}$, there is a remarkable paucity of historical explorations of this era from a Canadian perspective. Hence, the objective of this paper is to investigate specifically two research

From the Department of Clinical Neurosciences (AG), Departments of History and Community Health Sciences (FWS), University of Calgary, Calgary, Alberta, Canada. ReCeived April 2, 2013. Final Revisions Submitted November 1, 2013. Correspondence to: Aravind Ganesh, Neurology Department, Foothills Medical Centre, 140329 Street N.W., Calgary, Alberta, T2N 2T9, Canada.

Email: aganesh@ucalgary.ca. 
questions: What was the involvement of Canadian physicians in the study of MS during the period from 1850 to 1950 ? How was this development further influenced by research traditions of neurology and the study of MS in the rest of the Western world (Europe and the United States (US))? Articles selected for inclusion were either scripted during the "golden centenium" of MS, and were related to the diagnosis, aetiology, epidemiology, or treatment of MS; or if written after the Second World War (WWII), dealt with some aspect relevant to the history of the condition (also, see the Appendix). By exploring the emergence of MS as a well-characterized clinical entity in Canada, the evolution of its differential diagnosis, and Canadian attempts at resolving the enduring mysteries of the aetiology, epidemiology, and treatment of MS, this article shall examine the largely untold story of Canada's role in the fascinating chronicle of this central neurological disease.

\section{The Early Descriptions of MS and Clinical Research Encounters with Confounding Entities}

As suggested by various case histories of such eminent historical personalities as the Catholic Dutch mystic Saint Lidwina of Schiedam (1380-1433) ${ }^{8}$, King George III's grandson, the English nobleman Augustus Frederick d'Este (1794-1848) ${ }^{9}$, German poet and revolutionary Heinrich Heine $(1797-1856)^{10}$, or the English naturalist and children's writer Margaret Gatty (1809-1873) ${ }^{11}$, MS has likely been a component of human morbidity for centuries, long before the advent of medical investigations into the disease. The same may be said for Canada's medical history. One documented case raising strong suspicions of MS is that of William Brown (b. 1790), a 19th century trader with the Hudson's Bay Company at their York Factory post in North-East Manitoba, who began experiencing leg weakness and visual problems at age 21 in $1811^{12}$ :

[Brown] found it increasingly difficult to carry out his duties. When he felt he was too weak to withstand the rigors of a long survey assignment, he sent a replacement in his stead. For this he was censured by Governor Simpson, who felt Brown was neglecting his responsibilities. He had an intermittent and progressive disorder with visual symptoms, weakness, and gait difficulty. His symptoms progressed and he was eventually relieved of his post and returned to Scotland to be cared for by his family. He died a few years later ${ }^{6}$.

In many ways, this patient history is quite unique as a potential early case of MS, in that Brown was just an average man - the type of individual scarcely featured in medical evidence in the early modern period ${ }^{13}$. Lacking the dramatic or religious flair of Saint Lidwina of Schiedam, the literary prominence of Heine or Gatty, or the royal status of d'Este, Brown does not appear to have received any formal medical attention along the lines of either diagnosis or treatment, during his time in Canada. In the Hudson's Bay Company's harsh world of profit-driven trading and surveying on the Canadian frontier, there was no room for this young man's physically debilitating illness, and where Lidwina received praise and beatification, Brown received censure and termination of his job. It seems quite probable that in the early 19th century, many such early Canadians may have lived and died of this illness, their tribulations unwritten, their stories lost to the snowdrifts of history.

Although von Frerichs provided an earlier description of the disease in 1849, it is the French doyen of neurology, Jean-Martin Charcot (1825-1893) at the Salpêtrière Hospital in Paris who is recognized as having first made definite links between symptoms of MS - termed La sclérose en plaques - and postmortem pathological changes ${ }^{14}$. He is credited with giving the first complete histological account of MS lesions, describing the presence of demyelination, inflammation, and glial proliferation $^{15}$, and also described what came to be known as Charcot's triad - the combined symptoms of nystagmus, ataxia,

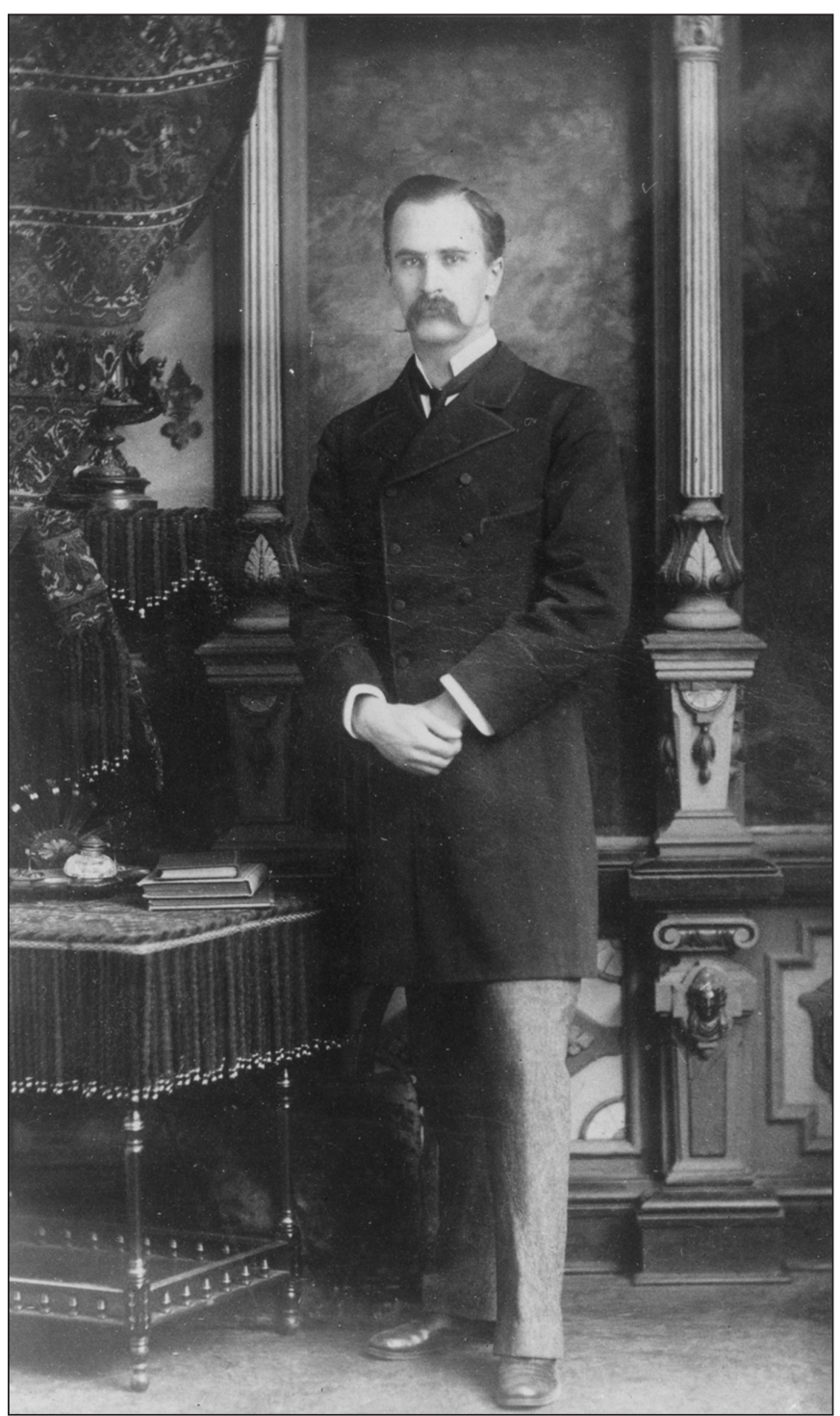

Figure 1: Full-length portrait of Sir William Osler (1849-1919) in Montreal, October 1881, from the William Osler Photo Collection at McGill University's Osler Library. 
and scanning speech ${ }^{14}$. In 1868 , he delivered his famous lectures on $\mathrm{MS}^{16}$ : lecture VI, describing the spinal, cephalic, and bulbar "forms" of MS; lecture VII, outlining the various symptoms including the Charcot triad; and lecture VIII, demonstrating the pathology of MS, with loss of myelin and persistent axons eventually becoming damaged ${ }^{17}$.

It was in the wake of Charcot's pioneering work that three cases of "insular sclerosis" of varying severity were presented by Sir William Osler (1849-1919) (Figure 1) in 1880 before the Medico-Chirurgical Society of Montreal $^{18}$ (Figure 2). These cases of MS appear to be the first publicly reported ones in English Canada. Osler described these cases in elaborate detail, and his approach to them was strongly reflective of the developments in neurology in the Western world at the time, particularly the approach of reconciling clinical features with findings on pathological specimens ${ }^{19}$. This is exemplified by the most severe case in the series (case III), that of a 45-year-old man who had deteriorated over several years, becoming emaciated and unable to speak, suffering from paresis of all extremities, sensory loss to light touch and pinprick, right ptosis, left arm contracture, as well as urinary and fecal incontinence, and who died five days after being examined. Osler remarked:

It is evident that we have only witnessed the close of the disease, and among the final symptoms, in addition to the paresis, contractures of the limbs often occur, most frequently of the legs ${ }^{18}$.

Osler then conducted an autopsy, reconfirming his diagnosis and further detailing the pathological basis of the disease. On microscopic examination of the sclerotic patches, he made the following observations:

In the wavy bundles of fibres crossing the central part of the small patches the fibers seem larger. The blood-vessels are numerous, full of corpuscles; many of them are fatty; in others, particularly the larger ones, there is an infiltration of leucocytes about the adventitia (perivascular lymph space) to an unusual extent ${ }^{18}$.

Osler's observations of the pathology of MS in this case, particularly the perivascular features, virtually imitate Charcot's aforementioned descriptions. Ever abreast with international literature, Osler connected his pathological findings suggestive of inflammation with German neurologist Ernst Viktor von Leyden's (1832-1910) observations at the University of Koenigsberg in East Prussia:

With regard to the pathology of the disseminated patches of induration have usually been regarded as the outcome of a slow, chronic, fibroid change - a sclerosis; but Leyden thinks that the process begins in scattered spots as an acute myelitis or encephalomyelitis, as the case may be. [...] He gives a remarkable case of this kind, presenting typical features of the disease, which after two relapses recovered completely ${ }^{18}$.

As Osler's case illustrates, early Canadian neurologists - like their contemporaries in Europe and the US - had to rely entirely on clinical features of the disease, details of the neurological examination, and sometimes even on post-mortem pathological features, to diagnose MS, in the absence of imaging technologies or laboratory testing during this period ${ }^{20}$. Neurologists at that
Re-printed from the "Canada Medical \& Surgical Journal," August, 1880.

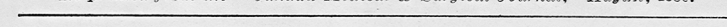

\section{CASES OF INSULAR SCLEROSIS.}

BY WM. OSLER, M.D., M.R.C.P., LoND.

Professor of the Institutes of Medicine, McGill University; Physician to the Montreal General Hospital.

(Read before the Medico-Chirurgical Society of Montreal.)

Gentlemen : I wish to bring under your notice this evening a form of Cerebro-Spinal Disease which has not yet engaged the attention of the Society, and of which, so far as I know, no cases have been reported in this country. It is characterized pathologically by the presence of numerous small spots of hardening, or sclerosis, throughout the brain and cord-hence the names insular, disseminated, multiple-and elnically by a variable yet well marked group of symptoms, among which a peculiar trembling of the limbs, motor pareses and an affection of the speech are the most prominent.

CASE I.-F. H., æt. 26, was sent to me for examination by Dr. Donald Baynes, on Nov. 21st, 1877. Patient is a tall, fair man, moderately well developed. Attention is at once directed to a peculiar trembling motion of the head and arms, and it is about this that he wishes advice. The following is the result of examination:-Motion-When perfectly at rest and the attention withdrawn from his condition, there are no movements, and nothing special is noticeable about the young man. When, however, the arms are lifted, the peculiar trembling begins, slight at first, then increasing somewhat; in the case

Figure 2: Opening page of Sir William Osler's (1849-1919) presentation in 1880 before the Medico-Chirurgical Society of Montreal, of the first cases of multiple sclerosis reported in the English Canadian literature. He immediately focusses on the tremor in Case I. From Osler's "Cases of Insular Sclerosis," Canada Medical and Surgical Journal 9, no. 1 (1880): 1-11.

time faced the unenviable challenge of differentiating MS from other confounding diseases, the most predominant of which were Paralysis agitans (the "Parkinson's Complex"), neurosyphilis, hysteria, as well as spinal cord and cerebellar tumours $^{21}$.

\section{Paralysis agitans}

Paralysis agitans was first named and described by the English physician James Parkinson (1755-1824) in his 1817 publication, "An Essay on the Shaking Palsy", identifying six cases, three of whom he had personally examined and the other three being cases he had observed on the streets of London ${ }^{22}$. The clinical description was refined by Charcot during 1868$1881^{23}$, who differentiated the slowness of movement or bradykinesia seen in these patients from weakness ${ }^{24}$. Charcot 
made considerable effort to distinguish MS from the nosological category of Paralysis agitans ${ }^{25}$, resulting in an excessive focus on the postural/action tremor sometimes also seen in $\mathrm{MS}^{24}$.

This focus is clearly illustrated by another one of the originally reported English Canadian cases of MS from Sir William Osler's 1880 presentation. The patient was a 26year-old man with dysarthria and an action tremor of the head and arms, suffering from severe dysmetria:

A glass of water lifted to the mouth is certain to be spilt, and on attempting to take a spoonful of soup or lift a bit of meat on a fork to the mouth, the irregularity of the movement is such that the food is much more likely to reach either ear ${ }^{18}$.

Although, with hindsight, this patient's presentation could be fully explained by cerebellar lesions alone, without multiple lesions spread across space or time as currently required for a diagnosis of $\mathrm{MS}^{26}$, Osler followed then-conventional Charcotian thinking and focussed on the patient's tremor, confidently diagnosing him with MS. He notes:

By a happy coincidence I had [Hermann] Engesser's [1846-1992] article in [Hugo von] Ziemssen's [18291902; Handbook] on Multiple Sclerosis before me when the patient came in, and the symptoms presented by him corresponded so closely with the description I had just read $[\ldots]$. The peculiar tremor, thought to be characteristic, was present in a most typical manner; the voice was also becoming scanning ${ }^{18}$.

Given that the characterization of MS and Paralysis agitans was still ongoing in Europe and the US in the late 19th century, neurologists were aware of the two conditions having overlapping features, but could not confidently differentiate between them. This appreciation of the importance of clinically differentiating between the two entities is well-reflected in Canadian publications. For instance, in 1879, before actual cases of MS were even being discussed in the English Canadian literature, the Canadian Journal of Medical Science published a tabular comparison of the two conditions from the Medical and Surgical Reporter ${ }^{27}$. This 1879 article accurately distinguished between the time course of both conditions, noting that with MS there is often a temporary remission of symptoms, and also recognized the tremors in MS as being action tremors. As might be expected with the incomplete and therefore unclear characterization of either disease entity at the time, the publication included several unpredictable criteria by which to distinguish between the two conditions, making a nonetheless bold and laudable attempt to provide a diagnostic scheme for physicians facing this clinical dilemma. For example, an interesting distinction was made between the two conditions based on the presence of sensory symptoms in Parkinson's Disease (PD), although sensory deficits are now known to be often quite prominent in $\mathrm{MS}^{28}$. The purported absence of gastrointestinal and urinary symptoms in PD mentioned in this table can also be contested today, owing to the recognition of non-motor disorders including autonomic dysfunction that are associated with the disease ${ }^{29}$. As well, the article excluded the cognitive deficits now known to be associated with PD as the disease ascends to the cortex ${ }^{30}$, and also the cardinal feature of postural instability secondary to loss of postural reflexes ${ }^{31}$.
Certain mortality rates of MS were also used with the conviction that these could serve as a distinguishing factor, in keeping with Charcot's perception of MS as a fatal ailment ${ }^{25}$.

As might be expected, the confusion of the clinical characterization of PD with MS-like symptoms often led to cases of misdiagnoses. On February 29, 1884, for example, Dr. J.B. McConnell (b. 1827?) presented the case of a 34-yearold railway engineer from Cambridge, England before the Medico-Chirurgical Society of Montreal. The engineer had been thrown violently to the ground in a railway collision two years prior, leaving him unconscious for ten weeks ${ }^{32}$. Following this, he found that he had an involuntary side-to-side tremor of his head that increased in frequency with action and settled when at rest. He had experienced discharge from his left ear continuously for some time after the accident, and now complained of pain over his left temple as well as vertigo and diplopia. While the history is highly suggestive of a severe traumatic brain injury ${ }^{33}$, McConnell focussed on the tremor and diagnosed the case as "local paralysis agitans, possibly asymptomatic"32. However, the tremor of PD is a rest tremor, rarely involving the head or neck, and the idiopathic disease is not produced by traumatic insults ${ }^{31}$. Nonetheless, in the debate that ensued, Osler did suggest that "the symptoms were not unlike those seen after removal of the vertical semicircular canals in pigeons" 32 , hitting close to an accurate diagnosis, while McConnell remarked:

In reply to Dr. Osler that it would be better classed as a case of multiple sclerosis, I may say that the fact of the affection occurring in one at his age, and being confined to the head, would favor that view; but, on the other hand, the definite movements occurring during rest, as well as during voluntary movements, and the fact that no paralysis exists as yet, although the tremor has lasted now a year and a half, are points which are generally supposed never to obtain in multiple sclerosis ${ }^{32}$.

The consideration of MS as a potential diagnosis even in this unusual context suggests that Canadian physicians, such as Osler and McConnell, had, by the late 19th century, become cognizant of the wide variety of presentations that are possible with the disease. As this case illustrates, however, translating knowledge about these various diseases into an accurate diagnosis in a clinical setting was an exceptionally challenging task.

Syphilis was another major confounder that the early neurologists encountered when contemplating a diagnosis of MS, given that the disease could invade the brain and/or spinal cord parenchyma. This could give rise to dementia paralytica ("general paresis of the insane") - a rapidly progressive dementia accompanied by personality changes -and/or tabes dorsalis ("locomotor ataxy") $)^{34}$. In fact, the causative agent of syphilis, the pale-coloured Tryponema pallidum, was itself only identified in 1905 by Fritz Schaudinn (1871-1906) and Erich Hoffmann (1868-1959) in their mutual laboratory at the Charite Hospital in Berlin ${ }^{35}$. The poor characterization of the disease had been reflected in a 1884 publication in The Canadian Practitioner that was entitled, "Locomotor ataxy not tabes dorsalis", wherein it was argued that locomotor ataxy is incorrectly associated with posterior sclerosis, and that the responsible lesions were in the postero-external column or "root zone of Charcot", while attributing the symptoms of tabes dorsalis to multiple peripheral neuritis ${ }^{36}$. 
Given the disseminated neurological features seen with both MS and neurosyphilis, early Canadian neurologists could easily confuse these conditions. For instance, consider the case presented to the Medico-Chirurgical Society of Montreal on June 27, 1884 by Dr. James Stewart (1847-1906) of McGill University ${ }^{37}$. The patient had vertigo, emotional lability, tremors, and other neurological symptoms that appear to be spread throughout the CNS. Once again, the doctor focussed on the tremor seen in this case, noting that "in the great majority of cases of disseminated sclerosis, tremor on voluntary movement is the most constant and most characteristic symptom present", leading Stewart to conclude that "the case is undoubtedly one of multiple cerebral sclerosis" 37 . However, in the presentation, the patient was noted to have a history of syphilis; in retrospect, this would make neurosyphilis the most likely diagnosis. Indeed, this possibility was astutely raised by Dr. Henry Howard (18151887) - superintendent of the insane asylum at Saint-Jean ${ }^{38}-$ in the discussion that followed the case presentation:

[Wilhelm Heinrich] Erb [1840-1921] says that out of 200 cases [of apparent sclerosis], 171 were syphilitic, and the cord was first affected. [My] own observations showed that seven out of ten had syphilis. A man in the asylum denied having had syphilis until the marks were found ${ }^{37}$.

Thus, Howard for one appears to have appreciated the importance of considering neurosyphilis as a possibility in such polysymptomatic neurological presentations, even if overt physical lesions are not seen, as in the case presented by Stewart.

\section{Spinal cord and cerebellar tumours}

Spinal cord and cerebellar tumours were also an important source of confusion when diagnosing MS. The distinction between these tumours and MS was of great practical significance, since with the former diagnosis, operative interventions could bring relief ${ }^{39}$. Interestingly, in the late 19 th and early 20th centuries, Canadian physicians often appear to have restricted their conception of MS to just a cerebral and spinal disease, failing to consider the cerebellum as a potential location for MS lesions. For example, a 1903 article in The Maritime Medical News discussing the differential diagnosis of vertigo included diseases of the vestibular system, toxic agents, pontine lesions, locomotor ataxia, as well as cerebellar tumours, and MS lesions of the cord ${ }^{40}$. Despite the impressively broad differential provided, there was no mention of the cerebellar lesions that can be caused by MS.

\section{Hysteria}

Hysteria was also a key confounder in the diagnosis of MS during the late 19th and early 20th centuries, given its diverse and polysymptomatic presentations, not unlike those caused by the diffuse lesions of $\mathrm{MS}^{41}$. Hysteria, in the form of what is now conventionally termed conversion disorder, came to the forefront of neurology through Charcot's work with his school, starting around 1870 until his death in $1893^{42}$. Charcot considered anaesthesias, hyperaesthesias, paralyses, and contractures to be the most important symptoms of hysteria, and made the key observation that the sensory complaints of hysterical patients often did not obey anatomical distributions, instead corresponding to popular perceptions of the body ${ }^{43}$.
By the early 20th century, the challenge of differentiating MS from hysteria, as Charcot had identified, was well-recognized by North American neurologists. At the 1917 American Medical Association meeting, for example, "the frequent mistaking of [MS] for hysteria" was pointed out, as "the characteristic striking remissions after very grave symptoms are misleading" (p. 1137) and often interpreted as recovery from pseudo-neurological features of hysteria ${ }^{44}$. This is well illustrated from a Canadian perspective by a case presented by Alfred Ernest Jones (18791958) - neurologist and Freud's official biographer - in a 1910 publication as demonstrator of medicine and psychiatry at the University of Toronto ${ }^{45}$. The case in question was that of a 22-year-old woman with neurological symptoms progressing over three years, presenting with hyporeflexia, muscle atrophy, and spasticity in both lower limbs, a sensory level involving absent sensation up to the waist, and urinary retention. The patient demonstrated some recovery, eventually able to take a few steps with assistance. A diagnosis of MS was eliminated on the basis of the assumption that "after three years one would expect to find other evidences of the disease, such as an intention tremor, nystagmus, ocular palsy, optic atrophy or the characteristic staccato speech" 45 . Similarly, other neurological causes were eliminated through consideration of their classical clinical presentations, and Jones concluded that the patient had "paraplegia of a hysteric nature" 45 . In retrospect, the reasoning given to dismiss MS seems unsound as patients are not required to demonstrate any of the mentioned symptoms ${ }^{2}$ and the current symptoms could be explained by a spinal cord lesion as might appear with progression of MS, or as transverse myelitis with remission ${ }^{46}$. In such a scenario, the atrophy may arise from disuse, and the hyporeflexia while atypical can be seen in about $5 \%$ of MS patients ${ }^{47,48}$.

A discussion of the challenges in the clinical characterization of MS and its differentiation from similar nosological entities during this era, would be incomplete without considering the issue posed by the neuro-psychiatric symptoms of MS. Although the early pioneers in MS such as Charcot and von Frerichs recognized the cognitive impairments often associated with MS, this knowledge was unfortunately soon discarded ${ }^{25}$. During the 19th century, only motor and sensory deficits related to identifiable lesions were considered relevant for the characterization of neurological diseases, with psychiatric and cognitive symptoms falling in the realm of the alienists - the forerunners of the psychiatrists - causing the importance of such symptoms in MS to be minimized ${ }^{49}$. It was not until the interwar period that new research, particularly the work of Sanger Brown (1852-1928) and Thomas K. Davis ${ }^{50}$, and Andre G. Ombredane's (1898-1958) 1929 study, Les Troubles Mentaux de la Sclérose en Plaques identifying dementia, psychosis, and affective disorders in $60 \mathrm{MS}$ patients, once again brought these symptoms to light ${ }^{51}$.

Paralleling these trends, there is virtually no discussion of the psychiatric aspects of MS in the English Canadian literature during 1850-1950. When these symptoms did come up in a case, the diagnosis typically favoured was general paresis of the insane. Consider the final case of the MS trio originally presented by Osler in 1880, that of a 44-year-old man, with an intention tremor of the left arm, dysarthria, a peculiar gait, and impotence for 1.5 years ${ }^{18}$. He had findings on exam of hyperreflexia, ankle clonus, involuntary movements of the tongue, 
lips, and facial muscles, and what would now be called a positive Romberg test - the man "cannot stand with eyes shut"18. While this presentation seems to suggest the presence of multiple upper-motor-neuron lesions consistent with MS, Osler noted that this patient had previously demonstrated peculiar behaviour and spent time in an asylum, leading Osler to consider the possibility of "general paralysis of the insane", although he ultimately favours MS due to the lack of progression of the patient's cognitive deterioration ${ }^{18}$.

\section{Clinical Signs and the Details of the Neurological Exam}

The vast differential diagnosis of MS clearly presented formidable challenges to early neurologists, particularly given the tremendous overlap of patient symptomatology for these various conditions. Therefore, in the mid-19th and early 20th centuries, active efforts were made by European and North American physicians to identify unique signs on the neurological examination that would allow them to more reliably differentiate between MS and similarly-presenting diseases. As these objective techniques were discovered by physicians in Europe and the US; Canadian doctors became more adept at differentiating MS from its mimics.

The Romberg Test for dorsal column pathology, devised by Moritz Heinrich Romberg (1795-1873) in 1846 ${ }^{52}$, had been adopted by Canadian neurologists involved in the study of MS by the end of the 19th century. This is evidenced by its indirect mention in Osler's aforementioned landmark presentation in 1880 , wherein a patient was described as unable to stand with his eyes closed ${ }^{18}$, and its mention by name ("Romberg's symptom") in a case presentation of MS at the 29th annual meeting of the Canadian Medical Association in $1896^{53}$. The propulsion/ retropulsion/lateropulsion component of the test, added by Romberg in 1855 , wherein the physician quickly pulls the patient forwards, backwards, or sideways by the shoulders while they stand ${ }^{54}$, would reveal postural instability, as often seen in PD and the Parkinson's plus syndromes ${ }^{31}$. Thus the Romberg Test may have been of significance for the early Canadian neurologists to differentiate MS from Paralysis agitans.

The deep tendon reflexes - now known as muscle stretch reflexes - were demonstrated in 1859 by the renowned Civil War neurologist Silas Weir Mitchell (1829-1914) as "a peculiar contraction" produced by a percussion hammer applied to a stretched tendon $^{55}$. It was in 1875 that these reflexes are known to have been first described in the context of clinical testing, independently by the German neurologists Wilhelm Heinrich Erb (1840-1921) at the University of Heidelberg and Karl Friedrich Otto Westphal (1833-1890) at the University of Breslau ${ }^{56}$. The Erb-Westphal sign - the absent patellar reflex in cases of tabes dorsalis - stood in contrast with the hyperreflexia typically seen with the upper-motor-neuron lesions of $\mathrm{MS}^{28}$, proving to be an instrumental factor in the differentiation of the two conditions. The careful assessment of reflexes was rapidly incorporated into physical examinations by Canadian neurologists. For instance, in a 1888 discussion of presentations similar to tabes dorsalis ("Pseudo-tabes") and methods to distinguish them, Dr. John Ferguson (1802-1883) of the University of Toronto quotes Julius Althaus (1833-1900): "if there be an ataxy with increase of the deep reflexes, then there is either disease in the lateral columns or insular multiple sclerosis" $" 57$. In 1908, a publication in The Canadian Practitioner and Review discussed the importance of reflexes in the diagnostic process, noting that when deciding between cerebellar tumours or MS, an extensor plantar reflex and/or absent abdominal reflex would suggest $\mathrm{MS}^{39}$. The review delivered as part of an address in medicine to the Canadian Medical Association on June 10, 1908 and reprinted in The Maritime Medical News - also noted that in a patient with gait ataxia, hyperreflexia and an extensor plantar reflex would favour a diagnosis of MS, whereas hypo- or areflexia would favour tabes dorsalis ${ }^{58}$. The accurate utilization of the extensor plantar reflex described in this paper, 12 years after this signe de l'éventail ("fanning sign") was first reported by Joseph Babinski (1857-1932), provides yet another illustration of Canadian neurologists remaining abreast with international advancements in the field. The same review also noted that "the pupil which fails to react to light while it preserves the possibility of reacting on accommodation" 58 would favour a diagnosis of neurosyphilis, referring to Scottish ophthalmologist Douglas Argyll Robertson's (1837-1909) famous sign ${ }^{59}$.

In the early 20th century, laboratory tests became available that further aided accurate diagnosis. In 1906, August von Wassermann (1866-1925), a German bacteriologist, together with Albert Neisser (1855-1916) and Carl Bruck (1879-1944), German dermatologists and venereologists, published the first serologic test for the diagnosis of syphilis ${ }^{60}$. The utility of the Wassermann Reaction was quickly recognized by Canadian neurologists, with a 1910 report in The Canadian Practitioner and Review on the history of the procedure and its importance noting that it can help distinguish "between multiple sclerosis and cerebrospinal syphilis; central gliosis and specific myelitis; in cases of intracranial pressure, whether [this is] due to malignant neoplasm or to syphilitic gumma" ${ }^{\text {. T1 }}$ The same paper also critically evaluated the test, highlighting its moderately low sensitivity of $75 \%$ and poor specificity - with positive results for such conditions as leprosy and scarlet fever - as recognized by investigators at the Harvard Medical School ${ }^{61}$. Another paper in The Maritime Medical News that year on spinal cord tumours noted that since MS and neurosyphilis may give similar symptoms as a spinal cord tumour, the Wassermann reaction could help "determine the specific character of the tumour" 62 .

Max Nonne (1861-1959) of Hamburg in Germany was one of the first neurologists to make use of the Wassermann reaction, using it to diagnose neurosyphilis in the cerebrospinal fluid $(\mathrm{CSF})^{63}$. The reaction's adoption by neurologists in diagnosing neurosyphilis marked the beginning of an important role for CSF analysis in the differentiation between $\mathrm{MS}$ and similar neurological conditions, and Canadian physicians were well informed of this trend. In 1907, for example, The Canadian Practitioner and Review ran a paper on the value of cytological examination of the CSF in the diagnostic process ${ }^{64}$, originally published in the Albany Medical Annals, by the German neurologist Friedrich Apelt (1877-1911) - who collaborated with Nonne and lent his name to the Nonne-Apelt Test, a sensitive qualitative test for globulin in the CSF, found to be frequently elevated in neurosyphilis ${ }^{65}$. In this paper, Apelt noted the presence of lymphocytosis in the CSF in cases of neurosyphilis, hypothesizing that this reflects the "enormous increase of cellular elements as found in ... syphilitic infections, tuberculous and other forms of meningitis" ${ }^{4}$. He also discussed 
his CSF studies in 134 patients, concluding that lymphocytosis could confirm the diagnosis of general paresis or tabes as it is seen in roughly $50 \%$ of those with manifest and long-standing syphilis, compared to MS and cerebral tumours in which fewer cases had been observed with elevated lymphocytes. Indeed, both the Nonne-Apelt tests and CSF cytological analysis were important tools in differentiating MS from neurosyphilis, as MS patients typically have fewer lymphocytes in the CSF than syphilitic patients $\left(5-30 / \mathrm{mm}^{3}\right.$ for MS versus as high as 1,000 for syphilis), and normal total protein concentrations ${ }^{66}$.

\section{Canada's Search - With the World - To Uncover the Causes and Epidemiology of MS, as well as Treatment Options}

Canadian neurologists were actively involved in efforts to explain the aetiology of MS, and like their contemporaries abroad, attempted various characterizations of its epidemiology and a wide variety of treatments. If we consider the historical epidemiology perspective, we find that early on in the period from 1850 to 1950, Canadian physicians appeared to have appreciated that MS was a disease afflicting young adults. In fact, even before Osler had presented the first Canadian cases of MS in 1880, the Canadian Journal of Medical Science's tabular comparison of MS and Paralysis agitans contrasted the appearance of MS during the ages of 20-45 years with the onset of paralysis agitans after 55 years-of-age. This tenet remained consistent with later 20th century publications, such as the 1922 review of the "ecology" of MS by the neurologist Charles Loomis Dana (1852-1935) at Cornell's Medical School in New York, which stated that patients ranged chiefly from 20-40 yearsof-age ${ }^{67}$.

Whereas Charcot had recognized a higher prevalence of MS in women ${ }^{25}$, by the early 20 th century, the reported gender ratio for MS in the literature had become skewed towards men, possibly facilitated by the seclusion of women with neurological symptoms to the nosological umbrella of hysteria, as discussed previously. In fact, a 1921 report from the Association for Research in Nervous and Mental Diseases on MS stated that "the male is more often affected than the female ... [at a ratio of] nearly 3 to $2 " 68$. However, a detailed survey of the Canadian literature suggests that not all physicians during this period may have embraced the predominant view of MS as a disease more common in men. For instance, an article on retro-bulbar optic neuritis in the Montreal Medical Journal in 1905 by renowned Scottish ophthalmologist Robert Marcus Gunn (1850-1909), that included MS in the differential diagnosis, surprisingly noted:

Syphilitic and tuberculous deposits in the optic nerve are the cause of rapid changes in the nerve. In this latter group may be included the so-called primary cases, e.g., those in insular sclerosis and those ascribed to influenza and gout; in the former recurrences are very likely to occur, and women are more frequently affected in primary cases than men ${ }^{69}$.

Nevertheless, in keeping with the American trends during this period, most of the cases of MS discussed in the Canadian literature were indeed male patients, and as previously discussed, there exist numerous cases where MS could very well have been a legitimate diagnosis but was either not considered or hastily dismissed. In this regard, historian Colin Talley's astute argument that better neurological training, improved diagnosis of female patients, better recognition of MS in its various forms, and more accurate differentiation of MS from similar neurological conditions, were the key factors accounting for the increase in the prevalence of MS in the US, particularly between 1920 and 1950, may also hold true for Canada ${ }^{21}$.

The period of 1850-1950 also saw Canadian participation in the development of new aetiological theories. In the mid-19th century, the search for the aetiology of MS received a boost from the promulgation of Germ Theory by the British physician and public health pioneer John Snow (1813-1858), who utilized the theory of an infectious pathogen to explain the 1854 cholera outbreak in England ${ }^{70}$. Neurologists began investigating various known infections as potential precipitants of MS symptoms, including malaria and typhoid. Canadian physicians actively followed and participated in these efforts; for instance, an 1893 review in the Ontario Medical Journal on the "leading forms of nervous disturbance attributed to specific malaria" as described by William Browning (1855-1941) - neurologist/psychiatrist who in 1894 introduced the lumbar puncture to the US ${ }^{71}$ - noted that "it has been held by some that cases of tabes and disseminated sclerosis are sometimes of malarial origin" 72 . In 1909, John George Adami (1862-1926), professor of pathology at McGill University ${ }^{73}$; Albert George Nicholls (1870-1946), professor of pathology at Dalhousie University and future editor of the Canadian Medical Association Journal ${ }^{74}$; along with Oskar Koltz (1878-1936), professor of pathology and bacteriology at the University of Toronto ${ }^{75}$, published a review in The Montreal Medical Journal ${ }^{76}$ wherein they reported that the ophthalmic or conjunctival test reaction for typhoid developed by the French bacteriologist Andre Chantemesse $(1851-1919)^{77}$ had been found to be positive in some cases of MS. Such research into infectious aetiologies for MS continues to this day, with one of the leading theories implicating molecular mimicry between the Epstein-Barr virus (EBV) and a self-protein in $\mathrm{MS}^{78}$.

Toxic aetiologies were also explored during this period, such as zinc, manganese, or mercury poisoning ${ }^{79}$. Some of the hypotheses tracked by Canadian physicians in this regard were remarkable in their modern outlook on medical research, diagnostics and therapeutics. For example, in 1897, The Canadian Practitioner ran an article by the celebrated American neurologist Ira Thompson Van Gieson (1866-1913) ${ }^{80}$ on the role of toxic agents in neurological and psychiatric conditions, which noted: "the greater the intensity and amount of the poison the greater is the effort of nature to protect herself by throwing out an exudate, and this in multiple sclerosis results in patches of sclerotic tissue" 81 . This idea of a natural protective response to a noxious agent propagating disease is consistent with the modern conceptualization of MS as resulting from an immune response spiralling out of control ${ }^{2}$.

In addition to toxic and infectious precipitants, Canadian neurologists also examined the question of whether there were genetic factors at play in the development of MS. The most significant contribution in this regard came from neurologist Roland Parks MacKay (1900-1968), trained at the University of Toronto, who endeavoured to collect all the published familial cases of MS, dating back to 1896, while at McGill University in 
Montreal in the 1940s. The Austrian neurologist Karl Johannes Thums (1904-1976) at the University of Prague had performed the first systematic study of the incidence of MS - in the National Socialism context of racial anthropology - using identical and fraternal twins in the 1930s, and concluded that there was no evidence for any genetic contribution towards $\mathrm{MS}^{82}$. However, MacKay astutely pointed out that Thums had "presented no evidence whatsoever concerning the zygosity of his twins" 83 . Therefore in his studies, for which he later collaborated with the pediatric researcher Ntinos Myrianthopoulos (1922-2000) at the National Institute of Health $^{84}$, he meticulously collected evidence to more confidently determine the zygosity of each twin pair encountered a complex and inexact task in a time predating DNA testing by several decades:

Genetic studies were directed toward establishing the type of zygosity in each twinship by comparing the two members with respect to (1) physical characteristics,

(2) fingerprints, and (3) major and minor blood groups, including ABO, MN, CDE ce, Kell, Duffy, and Lewis ${ }^{83}$.

To add further objectivity to his rigorous attempts at zygosity determination, MacKay also made use of biostatistical analysis using empirical figures of the frequency of these various characters in the population using data from contemporary genetic studies ${ }^{85}$. MacKay also insightfully recognized that one of the extant limitations in MS genetic studies was the risk of misdiagnosis inherent in accepting previously documented neurological diagnoses (MS or otherwise) for twins or family members as fact, without independent verification. Consequently, he carried out a meticulous appraisal on every twin and their relatives with neurological complaints, securing reports on any physical or CSF examinations, and then documenting a thorough physical examination and analyzing the gammaglobulin content of the CSF, remarking:

Only by such a procedure can our work be shielded from the criticism of the subjective bias of "diagnosis by intuition" 83 .

He then classified each individual as having definite or possible MS or no MS, using a set of diagnostic criteria he himself had set forth ${ }^{86}$, that anticipated the modern McDonald criteria of dissemination of lesions in space and time ${ }^{26}$, and skilfully combined clinical and laboratory data:

Our ideal standards have been fully set forth [...] as follows: (1) onset between 12 and 50 years-of-age, (2) dissemination of lesions in space, (3) dissemination of attacks in time, (4) generally increasing disability, (5) absence of evidence of syphilis (or other sclerosis simulating disease), (6) changes in colloidal gold curve and elevation of level of $\gamma$-globulin of the $\mathrm{CSF}^{87}$.

With these rigorous measures, MacKay studied 34 monozygotic and 26 dizygotic twin pairs, and an impressive total of 2,900 relatives, presenting his findings in a preliminary study ${ }^{83}$ and a follow-up study five years later ${ }^{87}$. He found that the concordance rate for MS was about $15-23 \%$ in monozygotic twins compared to around $10-21 \%$ in dizygotic twins - the lower and upper limits of these ranges representing fully concordant cases of definite MS and all possibly concordant cases of definite or possible MS, respectively. MacKay found that $22 \%$ of the relatives studied also had MS, with the familial prevalence being about 20 times that in the general population. While he recognized that the inheritance pattern did not perfectly fit a Mendelian pattern, he hypothesized that a pattern of "autosomal recessive inheritance with reduced inheritance" could be consistent with his observations ${ }^{87}$, and appropriately concluded that the development of MS involved both genetic and environmental factors. MacKay's findings have since been confirmed by more recent British and Canadian studies ${ }^{88,89}$, which have found concordance rates of $25 \%$ in monozygotic twins and $5 \%$ in dizygotic twins.

This era was also witness to a multiplicity of emerging treatments. From the beginning, despite their fledgling understanding of the disease, Canadian neurologists actively attempted various treatments to provide relief to their patients with MS. Treatments during this period can be classified as nonpharmacological, pharmacological, and procedural. Nonpharmacological interventions included lifestyle modifications, various diets, hydrotherapy, massages, and psychotherapy; while pharmacological interventions involved various chemicals like hyoscine/duboisin, cannabis, and atropine ${ }^{79}$. Procedural interventions included electrotherapy and more invasive nervestretching operations ${ }^{90}$.

One non-pharmacological treatment for MS, which endures to this day, is the low-animal-fat diet developed by the American neurologist Roy Laver Swank (1909-2008) in 1950 based on his study of dietary factors apparently associated with MS, while at the Montreal Neurological Institute (MNI) ${ }^{91}$. Swank's work tied in with similar research carried out in Paris, Wuerzburg, Toronto, and New York during this period ${ }^{92}$. Swank assessed the incidence of MS between 1935 and 1948 in 18 counties in Norway and found considerable variation between farmingdairying areas and fishing districts, as well as between inlands and coastal regions. He then assessed the preferred diets in these areas through seven-day recordings of food intake, and was convinced of a strong association between MS risk and butter fat (increased risk) and fish consumption (decreased risk) ${ }^{93}$. Inspired by Richard M. Brickner's (1896-1959) and Tracey Jackson Putnam's (1894-1975) theories of vessel pathology driving the development of $\mathrm{MS}^{94}$, Swank argued:

A search for a mechanism that could cause both an interference with, and slowing down of, the cerebral [...] blood flow, and breakdown of the blood-brain barrier in the CNS, leads to a consideration of the circulatory changes that have been observed in a number of species, including man, following large saturated fat meals ${ }^{95}$.

Presuming that high dairy-related fat contributed to MS risk through impaired vascular flow in the individuals, Swank advocated for consumption of a low animal fat diet as a means of altering blood lipids and coagulation ${ }^{96}$, and demonstrated the positive influences of such a diet on the lipid levels in MS patients ${ }^{97}$. Over a period of fifty years, during which he published several papers on the subject, Swank reported less progression of symptoms in MS patients who followed his dietary suggestions, when compared with foregoing published reports $^{98-100}$.

Perhaps owing to the paucity of efficacious therapeutic options, there was a tendency to rapidly extend the application of 
treatments that had apparent benefits for one neurological disease to numerous others; for instance, mercury, the staple of anti-syphilitic treatment attempts in the 19th century, was frequently tried in MS patients albeit without success ${ }^{79}$. A dramatic Canadian illustration of the broad extension of treatments to various neurological conditions is that of nervestretching, which was first performed to relieve the painful spasms of tetanus ${ }^{101}$. Soon, it was being used by Canadian neurologists and their colleagues abroad for tabes dorsalis, neuralgias, epilepsies, paralysis agitans, transverse myelitis, lateral sclerosis, muscular atrophy, as well as MS, as noted in a 1882 review of the procedure in The Canadian Journal of Medical Science ${ }^{90}$. The review hypothesized that the forced stretching of a nerve - the sciatic nerve, for example, being "stretched to $10 \mathrm{~cm}$ with a weight of 60 pounds" 90 - would cause the nerve to slide in its sheath, impairing its irritability and breaking up inflammatory adhesions.

Some treatments also took on a diagnostic value. In the 19th century, iodide of potassium, now typically used for various inflammatory dermatoses, as well as sporotrichosis and thyroid storms ${ }^{102}$, was recognized to help diminish the superficial lesions in syphilitic patients, with a 1896 report in The Maritime Medical News praising "the rapidity with which tertiary lesions such as periosteal nodes, skin eruptions, and iritis, disappear under its action" 103 . Perceiving this to be a reflection of a positive effect on the syphilitic infection itself, Canadian physicians appear to have used trials of the agent as a method to distinguish between neurosyphilis and multiple sclerosis. For instance, the author of the aforementioned review, one Dr. Samuel West (b. 1863?), describes a man whose symptoms "might have been due to advanced multiple sclerosis or even, except for want of mental symptoms, general paralysis of the insane, in whom no history of syphilis could be obtained"103. Iodide of potassium was prescribed and appeared to precipitate a rapid cure, leading West to conclude that "the case was doubtless of a syphilitic nature" 103 - although, in retrospect, this dramatic recovery could very well have been an instance of spontaneous remission from an attack of MS.

While certain pharmacological agents may have helped relieve such symptoms as spasticity and pain in MS patients, many of the early "curative" treatments for MS often did not have any physiological basis, and in retrospect appear to have bordered on quackery, with any improvements likely attributable to the placebo effect. Particularly with MS, remissions that are part of the natural history of the disease could be easily mistaken for positive consequences of therapy. Canadian physicians appear to have been perceptive of the poor evidence behind many of the purported treatments for MS and other neurological diseases at the time, as evidenced by an article in the year 1900 in The Maritime Medical News on quackery in the medical profession, which remarked that "incurable diseases are as babies in [the quack's] hands, and locomotor ataxia, multiple sclerosis, and epilepsy are his favourite bait"104. In the latter half of the 20th century, as systematic clinical trials became the norm in therapeutic research, Swank's reports on his diet was also heavily criticized for their lack of a randomized control group for comparison $^{105}$ or any form of blinding in his follow-up assessments $^{106}$. Nonetheless, these varied therapeutic attempts may be seen as reflecting the zeal of the profession, as physicians faced with suffering patients often experienced a strong emotional need to attempt treatments without waiting for a proof of efficacy, sustained by pressure from their patients ${ }^{107,108}$.

In addition to searching for treatments, Canadian physicians also recognized the importance of specialized support to MS patients given the immense complexity and burden of the disease. Following WWII, there was a push to establish MS clinics to pool larger groups of MS patients for organized documentation, assessment, and research programs ${ }^{109}$. The Montreal Neurological Hospital MS Clinic was the first specialized one in Canada, established in 1949 as a result of the efforts of Roy Swank, supported by Colin Kerr Russell (18771956), the founder of Neurology at the MNI. James Bert Ryal Cosgrove (1921?-1984) directed the clinic until his death in $1984^{110}$.

The post-WWII era also witnessed the emergence of patientdriven Multiple Sclerosis Societies, starting with Sylvia Lawry's (1915-2001) Association for Advancement of Research in Multiple Sclerosis (AARMS), born from her meeting with 20 leading neurologists in the field in March 1946 ${ }^{111}$. A year later, this would become the National Multiple Sclerosis Society. News of Lawry's work reached the ears of two visionary Canadians diagnosed with MS, both Montrealers - Evelyn Gottlieb Opal (1913?-1992), a housewife, and Harry H. Bell (1917-?), an engineer ${ }^{109}$. Opal had been diagnosed in 1936 at the age of 23 , and frustrated by the paucity of information available to patients with MS, formed a chapter of the American group in Montreal called the Dr. Colin Russell Chapter, named after her neurologist at the Montreal Neurological Institute ${ }^{112}$. Bell had been diagnosed in 1942, and having been in touch with Lawry regarding his vision of a research organization targeting MS, founded the Canadian MS Research Organization ${ }^{113}$. Lawry brought the two Montrealers together, resulting in the formation of the MS Society of Canada in 1948, with the renowned neurosurgeon Wilder Penfield (1891-1976) as honorary chairman of the scientific advisory committee ${ }^{109}$. The first grant from the fledgling society went to none other than Swank for his work on dietary intervention in MS, along with Donald Snell McEachern (1904-1951) ${ }^{114}$.

\section{Discussion}

The American neurologist Tracey Jackson Putnam (18941975) remarked that "the story of knowledge of multiple sclerosis is like a history of medicine in miniature" 115 . The statement is especially applicable to the Canadian story of MS investigations, discussed for the first time in this paper, as the developments in the field parallel the ongoing developments in disease characterization, medical technologies, and the evolution of neurology as a speciality, during 1850-1950.

In the first part of this manuscript, we have explored the emergence of $M S$ as a "distinct disease entity" in Canada and the challenges that arose in differentiating this clinical "chameleon" from similarly-presenting conditions. As illustrated by the case of young William Brown, MS likely had victims in Canada as in the rest of the world, long before the first descriptions of the disease as a distinct nosological entity emerged from the French and German schools later in the 19th century. It appears that Canadian physicians were following the literature of MS even before the first English Canadian cases were presented by 
Sir William Osler in 1880 , as demonstrated by the 1879 tabular comparison of paralysis agitans and MS discussed in this manuscript ${ }^{27}$. Thus, it would seem that the challenge of differentiating between MS and similar clinical disease entities was recognized by these early neurologists even before they had begun diagnosing or encountering MS in their own practices. Through the examination of each of Sir William Osler's three case presentations in 1880 , we have demonstrated how his reasoning closely matched the leading trends of the period, be it the detailed clinical descriptions for each case, his diligent use of autopsy to identify the distinctive pathological features of the disease, his emphasis on the tremor of MS given the early attempts to distinguish it from paralysis agitans, or his consideration of neurosyphilis as an alternative diagnosis when confronted with psychiatric symptomatology.

With regards to the broad and confusing differential diagnosis of MS, we have illustrated through various cases that Canadian neurologists were vulnerable to the same diagnostic challenges as their European and American contemporaries. While they do appear to have been aware of the confounding entities of paralysis agitans, neurosyphilis, nervous system tumours, and hysteria, often mentioning their reasons for excluding or favouring these diagnoses, they often lacked reliable clinical signs and examination techniques in the early period to arrive at accurate conclusions. The incomplete characterization of MS and these various mimics are evident in the literature, as alluded to repeatedly in this paper. However, even in case presentations where the diagnosis ultimately favoured may be challenged by modern disease conceptions, there was often a critical and wellreasoned debate among the physicians assembled, discussing alternative diagnoses, as illustrated by Osler's consideration of MS in J.B. McConnell's presentation of presumed local paralysis $\operatorname{agitans}^{32}$, or Henry Howard's consideration of neurosyphilis in James Stewart's presentation on $\mathrm{MS}^{37}$. Thus, didactic case presentations at various medical societies and their subsequent scholarly analysis by the assembled physicians, appear to have been a major avenue by which these early Canadian neurologists followed the dynamic characterizations of MS and similarlypresenting diseases during this period.

The second section of this manuscript discussed the evolution of new diagnostic techniques that enabled the distinction of MS from its entourage of differential diagnoses. Using various publications in the late 19th and early 20th century, specifically examining such examples as the Romberg Test, muscle stretch reflexes, and the Wassermann Reaction, we argued that Canadian physicians actively kept abreast of developments in clinical signs, examination techniques, and laboratory testing to more confidently differentiate between the nosological chameleon that was MS, and its various mimics. Moreover, Canadian neurologists appear to have been actively involved in the critical appraisal of these newly emerging medical technologies with respect to their clinical utility, as exemplified by the Canadian Practitioner and Review's aforementioned critique of the low sensitivity and poor specificity of the Wassermann reaction ${ }^{61}$.

The final section of this paper dealt with Canadian attempts at the resolution of three key enduring conundrums in the study of MS: namely those of epidemiology, aetiology, and treatment. In considering the historical epidemiology, it could be demonstrated that the Canadian medical research literature matches the international trends during this era, with most cases involving young male patients. In the rare case where a diagnosis of MS was considered for a female patient, it appeared that the alternative diagnosis of hysteria may have been favoured ${ }^{45}$, suggesting that the improved diagnosis of female patients with the evolution of neurology as a speciality may be closely tied with the apparent increase in the prevalence of MS in the late 20th century.

In addition, this article has presented fascinating aetiological theories for MS as they were discussed in Canadian medicine during this period, with two major camps - favouring either infectious or toxic aetiologies - becoming apparent in the literature. In this regard, MacKay's rigorous and meticulous study of monozygotic and dizygotic twin pairs and their relatives was ground-breaking in that it clearly demonstrated the additional role of genetic factors in the development of MS. Despite their day-to-day clinical struggles in accurately diagnosing MS, Canadian physicians appear to have been undeterred in their enthusiasm in seeking answers as to why their patients were suffering from this mysterious disease.

Canadian attempts at treatment were just as varied and intriguing, ranging from non-pharmacological and pharmacological therapies, to invasive surgeries like nervestretching. Mirroring the unclear characterization of the various neurological disease entities during this period, the available therapies also appear to have been applied generously to a varied host of diseases, with the lines between treatment for MS and competing diagnoses becoming rapidly blurred. While some physicians used treatments experimentally to confirm their diagnoses, as with Samuel West's use of iodide of potassium ${ }^{103}$, the evidence for most treatments was at best sparse, and Canadian physicians were keenly aware of the extant quackery, as illustrated through contemporary publications ${ }^{104}$.

In addition, the endurance of treatments like the Swank Diet to this day reflects the ardent desire of both Canadian physicians and their patients to attempt some form of relief for MS symptoms, despite a lack of definitive evidence. The postWWII period in particular saw the emergence of collaborative leadership in the field of MS between physicians and patients, which unfolded in Montreal in the form of specialized MS clinics driven by visionary neurologists like Swank, Russell, and Cosgrove , and the Canadian MS Society, with visionary patients like Evelyn Opal and Harry Bell at the helm. In contrast to the early days when Canadian MS patients like William Brown found themselves entirely helpless in the face of this debilitating disease, the new collaborative leadership resulted in an active investment by patients and their loved ones in the funding and evolution of MS research, providing them with a voice in the enduring international quest to develop more effective and lasting treatments.

There are several aspects of the Canadian history of MS which remain to be studied: for one part, the literature discussed in this paper originates primarily from various Canadian medical journals. Researching the vast body of archived historical documents penned by physicians and others that fall outside the realm of such formalized medical literature is likely to reveal several more cases of probable MS, many of which may predate the cases discussed here by several decades. For another part, this article has focussed on investigations in English Canada; a 
wealth of historical information awaits in the French-Canadian literature for comparative analysis. Ultimately, this analysis has provided a novel contribution to the scholarly literature in the form of a critical overview of the early Canadian explorations of MS, which can help further the medical profession's understanding of the history of this disease and the challenges it continues to present today.

\section{ACKNOWLEDGEMENTS}

The collaborative research presented in this article, as it ensued over the past three years, was supported by a "Hannah Summer Research Scholarship" awarded to Aravind Ganesh in 2010 by Associated Medical Services, Inc. in Toronto. In addition, Frank W. Stahnisch wishes to acknowledge support from the Mackie Family Collection in the History of Neuroscience, the Hotchkiss Brain Institute, and the Institute for Public Health (all: University of Calgary). Dr. Dawn Pearson (University of Calgary, Alberta), Dr. Scott Patten (University of Calgary, Alberta), and Dr. Jock Murray (Dalhousie University, Nova Scotia) offered invaluable encouragement for this project and provided reviews of earlier drafts of this manuscript.

\section{REFERENCES}

1. Compston A, Coles A. Multiple sclerosis. Lancet. 2002;359(9313): 1221-31.

2. Compston A, Coles A. Multiple sclerosis. Lancet. 2008;372(9648): 1502-17.

3. Frederikson S, Kam-Hansen S. The 150-year anniversary of multiple sclerosis: does its early history give an etiological clue? Perspect Biol Med. 1989;32(2):237-43.

4. Murray T. The history of multiple sclerosis: the changing frame of the disease over the centuries. J Neurol Sci. 2009;277(S1):S3-8.

5. Lassmann H. Multiple sclerosis pathology: evolution of pathogenetic concepts. Brain Pathol. 2005;15(3):217-22.

6. Murray T. Multiple sclerosis: the history of a disease. New York: Demos Medical Publishing; 2005. p. 31-2.

7. Beck C, Metz L, Svenson L, Patten S. Regional variation of multiple sclerosis prevalence in Canada. Mult Scler. 2005;11(5): 516-9.

8. Medaer R. Does the history of multiple sclerosis go back as far as the 14th century? Acta Neurol Scand. 1979;60(3):189-92.

9. Firth D. The case of Augustus d'Este (1794-1848): the first account of disseminated sclerosis. Proc R Soc Med. 1941;34(7):381-4.

10. Jeilinek E. Heine's illness: the case for multiple sclerosis. J R Soc Med. 1990;83(8):516-9.

11. Chambers T. Lecture XXIX on muscular atrophy. Lancet. 1864;347 (1):96.

12. Murray T. The saint, the king's grandson, the poet, and the Victorian writer: instances of MS when the disease did not have a name. IJMSC. 1999;3(2):1.

13. Stolberg M. Experiencing illness and the sick body in early modern Europe. Basingstoke: Palgrave-MacMillan; 2011. p. 41-7.

14. McDonald W. The dynamics of multiple sclerosis. J Neurol 1993; 240(1):28-36.

15. Charcot J. Histologie de la sclérose en plaques. Gazette des Hopitaux. 1868;41(1):554-66.

16. Clanet M. Jean-Martin Charcot. 1825 to 1893 . Int MS J. 2008;15 (2):59-61.

17. Charcot J, Sigerson Gt. Lectures on the diseases of the nervous system delivered at la Salpêtrière. London: New Sydenham Society; 1877.

18. Osler W. Cases of insular sclerosis. Can Med Surg J. 1880;9(1):111 (Quotes on p. 10, 5-9, 8-9, 3, 4, and 9-10 respectively).

19. Maulitz R. Morbid appearances: the anatomy of pathology in the early nineteenth century. New York: Cambridge University Press; 1987. p. 9-38.
20. Stahnisch F. Mind the Gap: Synapsen oder keine Synapsen? Bildkontrolle, Wortwechsel und Glaubenssaetze im Diskurs der morphologischen Hirnforschung. In: Stahnisch F, Bauer H, editors. Bild und Gestalt: Wie formen Medienpraktiken das Wissen in Medizin und Humanwissenschaften? Muenster: LITPress; 2007. p. 101-24.

21. Talley C. The emergence of multiple sclerosis, 1870-1950: a puzzle of historical epidemiology. Perspect Biol Med. 2005;48(3): 383-95.

22. Parkinson J. An essay on the shaking palsy. J Neuropsychiatry Clin Neurosci. 2002;14(2):223-36.

23. Lees A. Unresolved issues related to the shaking palsy on the celebration of James Parkinson's 250th birthday. Mov Disord. 2007;22(S17):S327-34.

24. Kempster P, Hurwitz B, Lees A. A new look at James Parkinson's essay on the shaking palsy. Neurology. 2007;69(5):482-5.

25. Butler M, Bennett T. In search of a conceptualization of multiple sclerosis: a historical perspective. Neuropsychol Rev. 2003;13 (2):93-112.

26. Polman C, Reingold S, Banwell B, et al. Diagnostic criteria for multiple sclerosis: 2010 revisions to the McDonald criteria. Ann Neurol. 2011;69(2):292-302.

27. Differential symptoms of multiple cerebro-spinal sclerosis and paralysis agitans. Can J Med Sci. 1879;4(6):159.

28. Olek M. Multiple sclerosis: etiology, diagnosis, and new treatment strategies; New York: Humana Press; 2005.

29. Zesiewicz T, Sullivan K, Amulf I, et al. Practice parameter: treatment of nonmotor symptoms of Parkinson disease: report of the Quality Standards Subcommittee of the American Academy of Neurology. Neurology. 2010;74(11):924.

30. Gross R, Siderowf A, Hurtig H. Cognitive impairment in Parkinson's disease and Dementia with Lewy Bodies: a spectrum of disease. Neurosignals. 2008;16(1):24-34.

31. Jankovic J. Parkinson's disease: clinical features and diagnosis. J Neurol Neurosurg Psychiatry. 2008;79(4):371.

32. Osler W. Society Proceedings - Medico-Chirurgical Society of Montreal, February 29th, 1884. Can Med Surg J. 1884;12(10): 598-605 (quotes on p. 0 and 1 respectively).

33. Xu J, Rasmussen I, Lagopoulos J, Haberg A. Diffuse axonal injury in severe traumatic brain injury visualized using high-resolution diffusion tensor imaging. J Neurotrauma. 2007;24(5):753-65.

34. Marra C. Update on Neurosyphilis. Curr Infect Dis Rep. 2009;11 (2): 127-34

35. Quetel C. Syphilis as a cultural phenomenon. In: Braddock J, Pike B, editors. History of Syphilis. Baltimore: Johns Hopkins University; 1992. p. 1-8.

36. Locomotor ataxy not tabes dorsalis Can Pract. 1884;9(2):44.

37. Rodger T. Society Proceedings - Medico-Chirurgical Society of Montreal, June 27th, 1884. Can Med Surg J. 1884;13(4):236-42 (Quotes on p. 40, 41 respectively).

38. Samuel R. Dictionary of Canadian Biography Online 2000 September 1, 2011 [cited 2012 September 9]; Available from: http://www.biographi.ca/

39. Russell J. The value of the reflexes in diagnosis. Can Pract Rev. 1908;33(9):563.

40. McCully $\mathrm{O}$. The clinical significance of vertigo. Maritime Med News. 1903;15(10):444-7.

41. Conversion Disorder. Diagnostic and statistical manual of mental disorders. 4 (text revision) ed. Washington: The American Psychiatric Association; 2000. p. 492-8.

42. Bogousslavsky J. Hysteria after Charcot: back to the future. Front Neurol Neurosci. 2011;29(1):137-61.

43. Charcot J. Neue Vorlesungen ueber die Krankheiten des Nervensystems insbesondere ueber Hysterie. Leipzig: Toeplitz and Deuticke; 1886.

44. Crafts L. The early recognition of multiple sclerosis. JAMA. 1917; 69(14):1130-7.

45. Jones A. The differential diagnosis of paraplegia. Can Pract Rev. 1910;35(1):1-8 (Quote on p. 7).

46. Brinar V, Habek M, Brinar M, Malojčić B, Boban M. The differential diagnosis of acute transverse myelitis. Clin Neurol Neurosurg. 2006;108(3):278-83. 
47. Shefner J, Mackin G, Dawson D. Lower motor neuron dysfunctuon in patients with multiple sclerosis. Muscle Nerve. 1992;15(11): 1265-70.

48. Misawa S, Kuwabara S, Mori M, Hayakawa S, Sawai S, Hattori T. Peripheral nerve demyelination in multiple sclerosis. Clin Neurophysiol. 2008;119(8):1829-33.

49. Butler M, Corboy J, Filley C. How the conflict between American psychiatry and neurology delayed the appreciation of cognitive dysfunction in multiple sclerosis. Neuropsychol Rev. 2009;19 (3):399-410.

50. Brown S, Davis T. The mental symptoms of multiple sclerosis. In: Dana C, Jelliffe S, Riley H, Tilney F, Timme W, editors. Multiple Sclerosis (Disseminated Sclerosis) - An investigation by the Association for Research in Nervous and Mental Diseases. New York: Hoeber; 1922. p. 98-104.

51. Berrios G, Quemada J. Andre G. Ombredane and the psychiatry of multiple sclerosis: a conceptual and statistical history. Compr Psychiatry. 1990;31(5):438-46.

52. Romberg M, Sieveking Et. A manual of the nervous diseases of man. London: Sydenham Society; 1853.

53. Roddick T. Society Proceedings - Canadian Medical Association. Twenty-ninth annual meeting, Montreal, August 26th, 27th and 28th, 1896. Montreal Med J. 1896;25(3):258-62.

54. Hunt A, Sethi K. The pull test: A history. Mov Disord. 2006;21(7): 894-9.

55. Louis E. Weir Mitchell's 1859 demonstration of "a peculiar contraction" produced by a percussion hammer. Neurology. 2008;70(12):969-73.

56. Louis E. Erb and Westphal: simultaneous discovery of the deep tendon reflexes. Semin Neurol. 2002;22(4):385-90.

57. Ferguson J. Pseudo-Tabes. Can Med Surg J. 1888;16(9):526-34 (Quote on p. 7).

58. Russell J. The value of reflexes in diagnosis - address in medicine, Canadian Medical Association, Ottawa, June 10, 1908. Maritime Med News. 1908;20(9):327-34 (Quote on p. 30).

59. Ravin J. Argyll Robertson: 'twas better to be his pupil than to have his pupil. Ophthalmology. 1998;105(5):867-70.

60. von Wassermann A, Neisser A, Bruck C. Eine serodiagnostische Reaktion bei Syphilis. Dtsch Med Wochenschr. 1906;32 (19):745.

61. Hoag D. The Wassermann reaction - its clinical value. Can Pract Rev. 1910;35(4):235-41 (Quote on p. 9).

62. Spinal cord tumors. Maritime Med News. 1910;22(4):99-101.

63. Nonne M. Clinical diagnosis of the syphilogenous diseases of the central nervous system. JAMA. 1909;53(4):286-96.

64. Apelt F. The significance of cytological examination of the cerebrospinal fluid. Can Pract Rev. 1907;32(7):419.

65. Nonne M, Apelt F. Ueber fractionierte Eiweissausfaellung in der Spinalfluessigkeit von Gesunden, Luetikern, functionell und organisch Nervenkranken und ueber ihre Verwertung zur Differentialdiagnose der Dementia paralytica, Tabes dorsalis, tertiaeren und abgelaufenen Syphilis. Arch Psychiatr Nervenkr. 1908;43(1):433-60

66. Multiple sclerosis. In: Holmes $\mathrm{H}$, editor. Professional guide to diseases. 9 ed. Philadelphia: Lippincott Williams and Wilkins; 2008. p. 224

67. Dana C. Multiple sclerosis and the methods of ecology. In: Dana C, Jelliffe S, Riley H, Tilney F, Timme W, editors. Multiple Sclerosis (Disseminated Sclerosis) - An investigation by the Association for Research in Nervous and Mental Diseases. New York: Hoeber; 1922. p. 43-8

68. Wechsler I. Statistics of multiple sclerosis. In: Dana C, Jelliffe S, Riley H, Tilney F, Timme W, editors. Multiple Sclerosis (Disseminated Sclerosis) - An investigation by the Association for Research in Nervous and Mental Diseases. New York: Hoeber; 1922. p. 26-43 (Quote on p. 34).

69. Gunn R. Retro-ocular neuritis. Montreal Med J. 1905;34(2):148.

70. Cameron D, Jones I. John Snow, the Broad Street Pump and modern epidemiology. Int J Epidemiol. 1983;12(4):393-6.

71. Rushmore J. William Browning, M.D. July 7, 1855-January 5, 1941. Bull Med Libr Assoc. 1893;29(3):185-6.

72. Nervous Affection Caused by Malaria. Ontario Med J. 1893;1 (8):347.
73. John George Adami. 1862-1926. J Pathol Bacteriol. 1927:30(1): 151-67.

74. Obituary - A.G. Nicholls. BMJ. 1946;1(4459):969.

75. Oskar Koltz 1878-1936. J Pathol Bacteriol. 1936;44(2):504-7.

76. Adami J, Nicholls A, Koltz O. The year's progress in bacteriology - the bacteriology of the infective diseases. Montreal Med J. 1909;38(5):341-5.

77. Hamburger W. The ocular typhoid reaction - preliminary report of a modification of the ocular test of Chantemesse. JAMA. 1908; 50(17):1344-5

78. Lang $\mathrm{H}$, Jacobsen $\mathrm{H}$, Ikemizu $\mathrm{S}$, et al. A functional and structural basis for TCR cross-reactivity in multiple sclerosis. Nat Immunol. 2002;3(10):940-3.

79. Camp C. Paralysis agitans and multiple sclerosis and their treatment. In: White W, Jelliffe S, editors. The modern treatment of nervous and mental diseases. Philadelphia: Lea and Febiger; 1913. p. 661-70.

80. White W. Dr. Van Gieson, an obituary. Am J Insanity. 1913;69(1): 801-3.

81. Van Gieson I. The relation of toxic agents to the production of nervous and mental diseases. Can Pract. 1897;22(5):358-9 (Quote on p. 9).

82. Thums K. Das Erblichkeitsproblem bei der Multiplen Sklerose. Muenchner Med Wchnschr. 1938;86(1):1634-8.

83. MacKay R, Myrianthopoulos N. Multiple sclerosis in twins and their relatives: preliminary report on a genetic and clinical study. Arch Neurol Psychiat. 1958;80(6):667-74

84. Myrianthopoulos N, MacKay R. Multiple sclerosis in twins and their relatives: genetic analysis of family histories. Acta Genet. 1960;10(1-3):33-47.

85. Smith S, Penrose L. Monozygotic and dizygotic twin diagnosis. Ann Human Genet. 1955;19(4):273-89.

86. MacKay R. The Familial Occurrence of Multiple Sclerosis and its Implications. Ann Intern Med. 1950;33(2):298-320.

87. MacKay R, Myrianthopoulos N. Multiple sclerosis in twins and their relatives: final report. Arch Neurol Psychiat. 1966;15(5): 449-62.

88. Willer C, Dyment D, Risch N, Sadovnick A, Ebers G. Twin concordance and sibling recurrence rates in multiple sclerosis. Proc Natl Acad Sci. 2003;100(22):12877-82.

89. Mumford C, Wood N, Kellar-Wood H, Thorpe J, Miller D, Compston D. The British Isles survey of multiple sclerosis in twins. Neurology. 1994;44(1):11-5.

90. Nerve-stretching. Can J Med Sci. 1882;7(4):119-20 (Quote on p. 20).

91. Swank R. Multiple sclerosis: a correlation of its incidence with dietary fat. Am J Med Sci. 1950;220(4):421-30.

92. Schaltenbrand G. Die Multiple Sklerose Des Menschen. Liepzig: Thieme; 1943.

93. Swank R, Lerstad O, Stroem A, Backer J. Multiple sclerosis in rural Norway: its geographic and occupational incidence in relation to nutrition. New Engl J Med. 1952;246(19):721-8.

94. Ganesh A, Stahnisch FW. On the historical succession of vesselbased therapies in the treatment of multiple sclerosis. Eur Neurol. 2013;70(1-2):48-58

95. Swank R, Duncan B. The Multiple Sclerosis Diet Book. New York: Doubleday; 1987.

96. Swank R. Treatment of multiple sclerosis with low-fat diet. Arch Neurol Psychiat. 1953;69(1):91-103.

97. Wilmot V, Swank R. The influence of low-fat diet on blood lipid levels in health and in multiple sclerosis. Am J Sci. 1952;223(1): 25-34

98. Swank R. Treatment of multiple sclerosis with low-fat diet: result of seven years' experience. Ann Intern Med. 1956;45(5):812-24.

99. Swank R. Multiple sclerosis: twenty years on low fat diet. Arch Neurol 1970;23(5):460-74.

100. Swank R, Goodwin J. Review of MS patient survival on a Swank low saturated fat diet. Nutrition. 2003;19(2):161-2.

101. Vogt P. Traumatic tetanus cured by stretching the nerves of the brachial plexus. BMJ. 1877;1(840):137.

102. Sterling J, Heymann W. Potassium iodide in dermatology: A 19 th century drug for the 21 st century - Uses, pharmacology, 
adverse effects, and contraindications. J Am Acad Dermatol. 2000;43(4): 691-7.

103. West S. Selection - rational therapeutics and the use of common remedies. Maritime Med News. 1896;8(7):216-26 (Quotes on p. 7 and 8 respectively).

104. Matters Medical - Quackery in the profession. Maritime Med News. 1900;12(9):337-8 (Quote on p. 337).

105.Lipids and multiple sclerosis. Lancet. 1990;336(8706):25-6.

106. Ben-Shlomo Y, Smith G, Marmot M. Dietary fat in the epidemiology of multiple sclerosis: has the situation been adequately assessed? Neuroepidemiology. 1992;11(4-6):214-25.

107. Byrnes C. The treatment of multiple sclerosis. JAMA. 1922;78(12):867-73.

108. Talley C. The treatment of multiple sclerosis in Los Angeles and the United States, 1947-1960. Bull Hist Med. 2003;77(4):874-99.

109. Murray T. The History of Multiple Sclerosis. In: Burks J, Johnson K, editors. Multiple Sclerosis: Diagnosis, Medical Management, and Rehabilitation. New York: Demos Medical Publishing; 2000. p. 27.
110. Boyer L. What is the history of the MUHC Multiple Sclerosis Program? 2003 July 82003 [cited 2013 July 25]; Available from: http://www.msclinic.ca/msweb/msprogram.htm

111. Talley C. The Combined Efforts of Community and Science: American Culture, Patient Activism, and the Multiple Sclerosis Movement in the United States. In: Packard R, editor. Emerging Illnesses and Society: Negotiating the Public Health Agenda. Baltimore: Johns Hopkins University Press; 2004. p. 39-70.

112. Evelyn Opal Society. 2009 August 10 [cited 2013 July 25]; Available from: http://mssociety.ca/legacy/pdf/Legacy $\% 20$ giving $\% 20$ brochure $\% 20 \mathrm{EN}$.pdf.

113. History. 201210 August 2012 [cited 2013 July 4]; Available from: http://mssociety.ca/en/community/mssc/history.htms

114. Penfield W. Donald Snell McEachern, M.D. 1904-1951. Arch Neurol Psychiat. 1952;67(2):267-8.

115. Putnam T. The centenary of multiple sclerosis. Arch Neurol Psychiat. 1938;4(4):806-13 (Quote on p. 813).

\section{Appendix: Search Strategy}

A search strategy was designed to capture the entire spectrum of literature pertaining to this topic. The expanded medical subject heading (MeSH - aligned with the classification of the National Library of Medicine, Bethesda, MA) term "Multiple Sclerosis/hi [History]", the French keyword "sclérose en plaques", as well as the German keywords "Multiple(n) Sklerose" and "Hirnsklerose" were used to search the electronic databases Medline, CAB Abstracts, Psycinfo, Psychbooks, Global Health, and the databases of the Canadian Society for the History of Medicine, the International Society for the History of Medicine, the Canadian Association for the History of Nursing, the New York Academy of Medicine, the Wellcome Library, the National Library of Medicine (including Locator-Plus and the Index-Catalogue of the Library of the Surgeon-General's Office), the Bulletin of the History of Medicine, EBSCO Host Historical Abstracts, Early Canadiana Online, as well as the Database of the History of Science, Technology, and Medicine. These searches generated roughly 1600 studies in English, French, German, and Italian. For the current review, over 700 English articles were screened for relevance, of which 106 articles have been incorporated into the manuscript. 